\title{
JIŘÍ LEVÝ: \\ LA TEORÍA DE LA TRADUCCIÓN Y LA LINGÜÍSTICA \\ JIŘÍ LEVÝ: \\ A TEORIA DA TRADUÇÃO E A LINGUÍSTICA
}

\author{
कर्थर \\ FERNANDO NAVARRO DOMÍNGUEZ \\ ANDRÉA CESCO (TRADUTORA)
}

Resúmen: Este trabajo intenta reflejar una aproximación al conocimiento del pensamiento traductológico de este autor, y esbozar o complejo paradigma Lingüística y Traducción. Pone en relación algunos trabajos de origen francés y de la misma época con la teoría de Levý, además de realizar una reflexión sobre el tema de la traducción de los nombres propios apoyándose en el trabajo de la profesora Králová.

\section{Introducción}

Uno de los primeros textos de Levý en el mundo hispano, en lengua castellana, es el que ofrece Miguel Ángel Vega ${ }^{1}$. La traducción de I. Cáceres hace referencia a un pasaje de la obra de Levý (1963) Uméní prekladu, titulado "Los dos modos de la traducción artística". Las reflexiones sobre el proceso traductor se refieren al ámbito de la
Resumo: Este trabalho tenta refletir um primeiro contato com o conhecimento do pensamento tradutológico deste autor, e esboçar o complexo paradigma Linguística e Tradução. Relaciona alguns trabalhos de origem francesa e da mesma época que a teoria de Levý, além de produzir uma reflexão sobre o tema da tradução dos nomes próprios apoiando-se no trabalho da professora Králová.

\footnotetext{
${ }^{1}$ Miguel Ángel Vega CERnUdA. Textos clásicos de teoría de la traducción. Madrid, Cátedra 1994 (2004), 348-350.
} 
traducción literaria.

Conviene subrayar algunos aspectos de este pasaje. Aquellos que hacen referencia a que "la base de la estética y crítica de la traducción es una categoría de valores", a las dos normas del arte de imitación "la de reproducción (que requiere fidelidad, correcta comprensión) y la norma artística" (que requiere belleza), y que el autor checo relaciona con los términos de traducción fiel y traducción libre. Levý recuerda que ambas cualidades son imprescindibles en la traducción y explica la relación del vínculo de los términos fidelidad y veracidad subrayando la importancia del valor cognoscitivo de la obra traducida: "La traducción no puede ser igual al original pero debe tener el mismo efecto sobre el lector".

Para realizar un trabajo tan delicado Levý plantea la necesidad de crear "una perspectiva traductológica" que permita la búsqueda de equivalencias estilísticas. Piensa que es difícil de alcanzar y que los dos métodos en uso (conservación de los medios del modelo o sustitución del estilo foráneo por uno equivalente en lengua meta) no consiguen buenos resultados. Entonces ¿cómo proceder?

Otro acercamiento a la obra y al pensamiento traductológico de Levý nos lo ha ofrecido J. Králová en la conferencia pronunciada en la Universidad de Alicante (UA) en abril de 2009. La profesora checa, después de recordar las obras del escritor (doy la traducción de los títulos ofrecidos por J. Králová): Teorías checas de la traducción (1957, 1996), Arte de la traducción (1963, 1983), ¿Será la teoría literaria una ciencia exacta? (1971) y otras publicadas en inglés y ao âmbito da tradução literária.

Convém destacar alguns aspectos desta passagem. Aqueles que fazem referência a que "a base da estética e da crítica da tradução é uma categoria de valores", às duas normas da arte da imitação, "a de reprodução (que requer fidelidade, correta compreensão) e a de norma artística" (que requer beleza), e que o autor tcheco relaciona com os termos de tradução fiel e de tradução livre. Levý lembra que ambas as qualidades são imprescindíveis na tradução e explica a relação de vínculo dos termos fidelidade e veracidade destacando a importância do valor cognoscitivo da obra traduzida: "A tradução não pode ser igual ao original, mas deve ter o mesmo efeito sobre o leitor".

Para realizar um trabalho tão delicado, Levý expõe a necessidade de criar "uma perspectiva tradutológica" que permita a busca de equivalências estilísticas. Ele pensa que é difícil de alcançar e que os dois métodos em uso (conservação dos meios do modelo ou substituição do estilo forâneo por um equivalente na língua meta) não conseguem bons resultados. Então, como proceder?

Outro acercamento à obra e ao pensamento tradutológico de Levý nos foi oferecido por J. Králová, na conferência pronunciada na Universidade de Alicante (UA), em abril de 2009. A professora tcheca, depois de lembrar as obras do escritor (dou a tradução dos títulos oferecidos por J. Králová): Teorías checas de la traducción (1957, 1996), Arte de la traducción (1963, 1983), ¿Será la teoría literaria una ciencia exata? (1971) e outras publicadas em inglês e a- 
alemán, señala la escasa difusión del pensamiento de Levý en el ámbito internacional y lo justifica por ser el checo lengua minoritaria y por el difícil y largo periodo histórico que ha vivido su país en el siglo XX. Veamos un resumen de lo dicho por la profesora Králová en su conferencia en la UA.

\section{La aportación de Levý al mundo de la traducción}

J. Králová presenta el pensamiento de Levý en torno a tres ejes: (1) La concepción de la traducción como proceso comunicativo, (2) La problemática de la traducción de los nombres propios y (3) La traducción como proceso comunicativo entre autor y traductor.

a) La traducción como proceso comunicativo en el ámbito literario es uno de los postulados teóricos defendido por Levý. Králová entiende que puede aplicarse a la traducción en su dimensión pragmática, pues la idea de Levý es el estudio de la relación entre mensaje original total y la estructura de éste. El estudio de los tres niveles en los que trabaja el traductor (descodificación, interpretación y nueva codificación) no debe circunscribirse a la aplicación de postulados lingüísticos o literarios sino que debe tener en cuenta otras ramas de saber: la psicolingüística, la antropología estructural, la semántica y cuantas disciplinas conexas, en boga en la década de los sesenta, puedan ayudar al estudio del proceso comunicativo. También la comparación de traducciones - varias versiones lingüísticas de una misma obra - ayudan a evaluar ganancias y pérdidas. $\mathrm{Y}$ esto es cierto pues la bibliografía especializada sobre el tema registra numerosas lemão, destaca a escassa difusão do pensamento de Levý no âmbito internacional e o justifica por ser o tcheco uma língua minoritária e pelo difícil e longo período histórico que seu país viveu no século XX. Vejamos um resumo do que foi dito pela professora Králová em sua conferência na UA.

\section{A contribuição de Levý para o mundo da tradução}

J. Králová apresenta o pensamento de Levý em torno de três eixos: (1) A concepção da tradução como processo comunicativo, (2) A problemática da tradução dos nomes próprios e (3) A tradução como processo comunicativo entre autor e tradutor.

a) A tradução como proceso comunicativo no âmbito literário é um dos postulados teóricos defendido por Levý. Králová entende que pode ser aplicado à tradução em sua dimensão pragmática, pois a ideia de Levý é o estudo da relação entre mensagem original total e a estrutura desta. O estudo dos três níveis nos quais trabalha o tradutor (decodificação, interpretação e nova codificação) não deve ser circunscrito à aplicação de postulados linguísticos ou literários, mas deve levar em conta outros ramos do saber: a psicolinguística, a antropologia estrutural, a semântica e quantas disciplinas conexas, em voga na década dos sessenta, possam ajudar o estudo do processo comunicativo. Também a comparação de traduções - várias versões linguísticas de uma mesma obra ajudam a avaliar ganhos e perdas. E isso é certo porque a bibliografia especializada sobre o tema registra numerosos trabalhos de avaliação de um mesmo texto traduzido e re- 
trabajos de la evaluación de un mismo texto traducido y retraducido a la larga del tiempo.

Un aspecto esencial de la teoría de Levý es aquel que desarrolla en Translation as a Decision Process $^{2}$ en el que afirma que la actividad traductora es un proceso de decisión donde el traductor debe optar por dos tipos de recorrido: las instrucciones delimitativas (los diferentes repertorios de los que dispone el idioma) y las instrucciones selectivas (la elección del medio lingüístico concreto). $\mathrm{Y}$ en este punto debemos fijarnos que cuando el traductor opta por una correspondencia (término empleado por Králová) de denominación más general, eliminando así los rasgos semánticos especiales del texto, el resultado es de pérdida. Estudios recientes $^{3}$ apuntan a que la lengua traducida es más sencilla, en recursos estilísticos, que el original: el proceso de simplificación es uno de los universales de los textos traducidos. Otro tanto podría decirse de la actitud del traductor cuando explica aspectos difíciles del texto para hacerlo accesible al público, meta en la que la traductología llama técnica de explicitación. Se trata de otro universal del lenguaje traducido.

b) La traducción de los nombres propios es otro tema clave en la disertación de la profesara Králová en su deseo de divulgar el pensamiento de Levý. Este tema tiene un tratamiento más extenso en el artículo de la autora "Proper Names in Inter-cultural Communi- traduzido ao longo do tempo.

Um aspecto essencial da teoria de Levý é aquele desenvolvido em Translation as a Decision Pro$\operatorname{cess}^{2}$ no qual afirma que a atividade tradutora é um processo de decisão em que o tradutor deve optar por dois tipos de trajeto: as instruções delimitativas (os diferentes repertórios que o idioma dispõe) e as instruções seletivas (a escolha do meio linguístico concreto). Neste ponto devemos observar que quando o tradutor opta por uma correspondência (termo empregado por Králová) de denominação mais geral, eliminando assim os traços semânticos especiais do texto, o resultado é de perda. Estudos recentes $^{3}$ apontam que a língua traduzida é mais simples, em recursos estilísticos, que o original: o processo de simplificação é um dos universais dos textos traduzidos. Outras coisas poderiam ser ditas sobre a atitude do tradutor quando explica aspectos difíceis do texto para torná-lo acessível ao público, meta que a tradutologia chama de técnica de explicitação. Trata-se de outro universal da linguagem traduzida.

b) A tradução dos nomes próprios é outro tema-chave na dissertação da professora Králová, em seu desejo de divulgar o pensamento de Levý. Este tema tem um tratamento mais extenso no artigo da autora "Nomes Próprios na Comunicação Intercultural: da

\footnotetext{
${ }^{2}$ Jiří LEVÝ. "Translation as a Decision Process", in To Honor Roman Jakobson II. The Hague, Mouton 1967,1171-1182.

${ }^{3}$ Gloria CORPAS. Investigar con corpus en traducción: los retos de un nuevo paradigma. Frankfurt, Peter Lang, 2008.
} 
cation: from Prescription to Description"4.

Es difícil identificar la esposa del protagonista de un texto cuando cada una mantiene su apellido, señala Králová. Levý ofrece tres vías de comportamiento en este tema: (1) traducción en el sentido estricto de la palabra - calcos -, (2) substitución y (3) transcripción. Levý explica el procedimiento para optar en un sentido o en otro y subraya que la elección de la traducción adecuada debe fundamentarse en razones de tipo literario e histórico - época - y de textualidad. Y aquí cabe reseñar la importancia de la visión histórica de los problemas traductológicos tal como recuerda el autor checo al referirse a la traducción en la época romántica. En este sentido se pronuncian también dos investigadores de relieve, en sendas obras: Michel Ballard y Lieven D'Hulst ${ }^{5}$.

c) La comunicación estética entre autor y lector es otra de las clave del éxito en la traducción. La traducción ejerce una influencia unificadora en el panorama de la Literatura Universal, o como señala Králová "un factor que aumenta la entropía" o "un factor de la continúa uniformidad de la Literatura Universal". Marion Böhler ha dirigido una obra titulada L'écrivain et son traducteur en Suisse et en Europe $e^{6}$ en la que recoge los testimonios de cinco traductores con sus autores, así como una reflexión muy interesante sobre temas colaterales, todos ellos relacionados con
Prescrição a Descrição"4.

É difícil identificar a esposa do protagonista de um texto quando cada uma mantém o seu sobrenome, destaca Králová. Levý oferece três vias de comportamento neste tema: (1) tradução no sentido estrito da palavra - calcos -, (2) substituição e (3) transcrição. Levý explica o procedimento para optar por um sentido ou outro e ressalta que a escolha da tradução adequada deve se fundamentar em razões de tipo literário e histórico - época - e de textualidade. E aqui cabe apontar a importância da visão histórica dos problemas tradutológicos tal como lembra o autor tcheco ao referir-se à tradução na época romântica. Neste sentido dois pesquisadores de destaque também se pronunciam em suas respectivas obras: Michel Ballard e Lieven D'Hulst ${ }^{5}$.

c) A comunicação estética entre autor e leitor é outro ponto fundamental para o sucesso na tradução. A tradução exerce uma influência unificadora no panorama da Literatura Universal, ou como destaca Králová "um fator que aumenta a entropia" ou "um fator da contínua uniformidade da Literatura Universal". Marion Böhler dirigiu uma obra intitulada L'écrivain et son traducteur en Suisse et en Europe 6 em que reúne testemunhos de cinco tradutores com seus autores, assim como uma reflexão muito interessante sobre temas paralelos, todos eles relacionados

\footnotetext{
4 Jana KRÁLOVÁ. "Proper Names in Inter-cultural Communication: from Prescription to Description", in Jana KRÁLOVÁ - Zuzana JetTMAROVÁ et al., Tradition versus Modernity. Praha, Univerzita Karlova v Praze, 2008, 89-100.

${ }^{5}$ Michel BALlaRD. "De Cicéron à Benjamin y Lieven d'Hulst (1990)", Cent ans de théorie française de la traduction. De Batteux à Littré (1748-1847). Lille, Presses universitaires de Lille, 1995.

${ }^{6}$ Marion BÖHLER. L'écrivain et son traducteur en Suisse et en Europe. Genéve, E-Zoé, 1998.
} 
la comunicación estética entre autor y lector.

La parte final del discurso de la profesora Králová es una síntesis de la aportación de Levý en su dimensión metodológica como precursor de una serie de postulados: integración de la Lingüística y la Ciencia literaria, conceptualización de la estructura como nexo entre forma y contenido, el papel creador del traductor, el esfuerzo por una explicación detallada de las normas, etc. Todo ello permite pensar que Levý se adelanta bastantes años a algunas de las preocupaciones de la investigación traductológica actual.

En otra contribución mencionada anteriormente ${ }^{7}$, Králová aplica los conceptos de la Escuela de Praga de centro y periferia a la traducción de los nombres propios (personales, topográficos e institucionales) para demostrar que los nombres propios, como fenómeno periférico, penetran en el centro del (poli)sistema receptor y viceversa sin necesidad de recurrir a medidas prescriptivas. Interesante contribución que pone sobre el tapete el tema del nombre propio como representación de una unidad polifuncional en tanto que componente específico de cada cultura.

Entre los autores españoles referenciados por la profesora Králová que tratan este tema figuran Rosa Rabadán, Virgilio Moya, Sales Salvador y Arregui Baragán ${ }^{8}$. En cuanto a otros autores, mencio- com a comunicação estética entre autor e leitor.

A parte final do discurso da professora Králová é uma síntese da contribuição de Levý em sua dimensão metodológica como precursor de uma série de postulados: integração da Linguística e da Ciência Literária, conceitualização da estrutura como nexo entre forma e conteúdo, o papel criador do tradutor, o esforço por uma explicação detalhada das normas, etc. Tudo isso permite pensar que Levý se adianta em vários anos a algumas das preocupações da pesquisa tradutológica atual.

Em outra contribuição mencionada anteriormente ${ }^{7}$, Králová aplica os conceitos da Escola de Praga, de centro e periferia à tradução de nomes próprios (pessoais, topográficos e institucionais) para demostrar que os nomes próprios, como fenômeno periférico, penetram no centro do (poli)sistema receptor e vice-versa sem necessidade de recorrer a medidas prescritivas. Interessante contribuição que coloca em questão o tema do nome próprio como representação de uma unidadde polifuncional enquanto componente específico de cada cultura.

Entre os autores espanhóis referenciados pela professora Králová que tratam deste tema, estão Rosa Rabadán, Virgilio Moya, Sales Salvador e Arregui Baragán ${ }^{8}$. Quanto a outros autores, menciona,

\footnotetext{
${ }^{7}$ KRÁLOVá, op. cit.

${ }^{8}$ Rosa RABADÁN. Equivalencia y traducción. León, Universidad de León, 1991; Virgilio MoYA. La traducción de los nombres propios. Madrid, Cátedra 2000; Dorotea SALES SALVADOR. "Conversation with Itamar Even- Zohar about Literary and Culture Theory, Comparative Literature and Culture", in WWWeb Journal, 2002; Natalia ARREGUI BARAGÁN (2006). "La traducción de alusiones culturales: los antropónimos", in Sonia BRAVO UTRERA, S. \& Rosario GARCÍA LÓPEZ, R. (coords.). Estudios de traducción: problemas y perspectivas. Las Palmas de G. C., Universidad, 2006, 187-196.
} 
na entre otros, a los checos Levý, Knappová $^{9}$, a la norteamericana Mougoyanni $^{10}$ y al alemán Fischer $^{11}$. Siguiendo las pautas establecidas por los autores checos Králová ofrece la siguiente taxonomía: Calco, préstamo, sustitución, explicitación y generalización. El análisis resulta interesante porque esboza los problemas entre lengua origen y lengua meta en los puntos siguientes: la influencia de la estructura interna, los aspectos sociológicos (asimetría cultural, internacionalización lingüística, aspectos sociolingüísticos, condicionamientos históricos de la norma) y las funciones del texto y género. Finalmente la autora propone solucionar el tema de la polifuncionalidad de los nombres propios en la traducción aplicando el concepto de centro-periferia. Para explicar este concepto Králová recoge la explicación de Sales Salvador ${ }^{12}$ quien afirma que la periferia ejerce una presión sobre modas dictadas por centros hegemónicos y busca alternativas, adoptando diferentes formas de integración, tanto en el campo de la lingüística como en el de los estudios literarios. Por eso, elementos centrales del polisistema origen pueden ser elementos periféricos en el polisistema meta y viceversa. La autora ilustra su explicación con ejemplos en lengua española y checa y defiende el concepto de centro- periferia en el tratamiento de la traducción de los nombres propios ya que éstos son recursos lingüísticos poli funcionales especí- entre outros, os tchecos Levý e Knappová $^{9}$, a norte-americana Mougoyanni $^{10}$ e o alemão Fischer $^{11}$. Seguindo os modelos estabelecidos pelos autores tchecos, Králová oferece a seguinte classificação: calco, empréstimo, substituição, explicitação e generalização. A análise parece interessante porque esboça os problemas entre língua de origem e língua meta nos seguintes pontos: a influência da estrutura interna, os aspectos sociológicos (assimetria cultural, internacionalização linguística, aspectos sociolinguísticos, condicionamentos históricos da norma) e as funções do texto e do gênero. Finalmente a autora propõe solucionar o tema da polifuncionalidade dos nomes próprios na tradução aplicando o conceito de centroperiferia. Para explicar este conceito Králová toma a explicação de Sales Salvador ${ }^{12}$ que afirma que a periferia exerce uma pressão sobre modas ditadas por centros hegemônicos e busca alternativas, adotando diferentes formas de integração, tanto no campo da linguística como no dos estudos literários. Por isso, elementos centrais do polissistema de origem podem ser elementos periféricos no polissistema meta e vice-versa. A autora ilustra a sua explicação com exemplos na língua espanhola e tcheca e defende o conceito de centro-periferia no tratamento da tradução dos nomes próprios, já que estes são recursos linguísticos polifuncionais específicos e manifestação signifi-

\footnotetext{
9 Jiří LEVÝ 1963 (1983). Milena KNAPPOVÁ. "K překládání osobních jmen", in Naše řeč 66. Praha 1983,169-173.

${ }^{10}$ Christina Mougoyanni. "Antroponimia y toponimia. Estrategias de traducción", in Folia Translatologica 8. Praha 2001,44-60.

${ }^{11}$ Martin B. FISCHER. "Plaza Potsdamer - ida y vuelta. Topónimos alemanes en la prensa española". BRAVO UTRERA \& GARCÍA LÓPEZ, (coords.). op. cit., 227-241.

${ }^{12}$ SALES SALVADOR. op. cit.
} 
ficos y a la vez manifestación significante de la "extranjería" de un texto.

\section{Levý y sus reflexiones teóricas sobre la traducción: el marco histórico}

Es difícil valorar la aportación de Levý a la traductología con los datos referenciados anteriormente pues sin una lectura atenta a los textos en lengua checa (lengua que yo no conozco) no creo que pueda realizarse una valoración de su, aparentemente, intenso análisis de los problemas. Por tanto me limito a ofrecer algunas consideraciones.

En primer lugar situaré al autor en el marco histórico de los grandes textos de traductología de la década de los sesenta del siglo pasado, en particular me detendré en autores franceses. En segundo lugar, retornaré el análisis iniciado por Králová de las contribuciones españolas en el campo de la traducción de los nombres propios $\mathrm{y}$, finalmente, presentaré un esbozo de la relación Traducción \& Lingüística desde Levý hasta nuestros días.

1 Levý y sus contemporáneos: el interés por la traducción literaria

La aportación relevante en el periodo mencionado de los años sesenta en Francia es la obra de Georges Mounin ${ }^{13}$. Lingüista y teórico de la traducción, Mounin nos ha dejado una decena de obras en los campos de la Linguística y de la Traductología entre las que cabe destacar una historia de la traducción (Teoria e storia de la traduzione, 1965), una monografía sobre cante da "estrangeiridade" de um texto.

\section{Levý e suas reflexões teóricas so- bre a tradução: o marco históri- co}

É difícil avaliar a contribuição de Levý à tradutologia com os dados referenciados anteriormente, pois sem uma leitura atenta dos textos na língua tcheca (língua que não conheço), não acredito que possa ser realizada uma avaliação de sua, aparentemente, intensa análise dos problemas. Assim me limito a oferecer algumas considerações.

Em primeiro lugar situarei o autor no marco histórico dos grandes textos de tradutologia da década de sessenta do século passado, em particular detendo-me em autores franceses. Em segundo lugar, retornarei à análise iniciada por Králová sobre as contribuições espanholas no campo da tradução dos nomes próprios e, finalmente, apresentarei um esboço da relação Tradução \& Linguística, de Levý até nossos dias.

1 Levý e seus contemporâneos: o interesse pela tradução literária

A contribuição relevante no período mencionado dos anos sessenta na França é a obra de Georges Mounin ${ }^{13}$. Linguista e teórico da tradução, Mounin nos deixou uma dezena de obras nos campos da Linguística e da Tradutologia, entre as quais vale destacar, uma história da tradução (Teoria e storia de la traduzione, 1965), uma monografia sobre a tradução auto-

\footnotetext{
${ }^{13}$ Georges MounIN. Les problemes théoriques de la traduction. Paris, Gallimard, 1963.
} 
la traducción automática ( $L a m a$ chine à traduire, 1964), decenas de artículos y, sobre todo, sus Problèmes théoriques de la traduction. Sin embargo, otros autores también reflexionan sobre la traducción, en particular la literaria, en este periodo, son E. Cary ${ }^{14}$, J. P. Vinay y J. Darbelnet $^{15}$ (1958) y algunos años antes, Valery Larbaud (1946).

Mounin $^{16}$ ofrece en su obra un estudio exhaustivo de la relación entre Linguística y traducción (capítulos 1,2 y 3 ) y esboza, a continuación, su teoría en torno a tres temas: el sentido, la visión del mundo y las múltiples civilizaciones en torno a la traducción. No deja, sin embargo, descuidada la traducción literaria a la que dedica varios artículos, en particular "La notion de qualité en matière de traduction littéraire" (1963). Mounin parte de la idea de J. Whatmough ${ }^{17}$ (1956) de que "los universales del lenguaje son rasgos comunes que encontramos en todas las lenguas" y la relaciona con los universales lingüísticos que no son más que una parte de un concepto algo mayor: los universales culturales. Recordamos esta frase de Mounin "lourde de sens": "La traduction est une opération curieuse sur le langage et la pensée".

Con E. Cary nos encontramos al profesional de la traducción en ejercicio, en Ginebra (muere en accidente de aviación en 1966) que ha podido ofrecer a la comunidad científica dos libros importantes: Comment faut-il traduire? (1953) y La traduction dans le monde moderne (1956). Cary se opone al mática (La machine à traduire, 1964), dezenas de artigos e, principalmente, seus Problèmes théoriques de la traduction. Entretanto, outros autores também refletem sobre a tradução neste período, particularmente a literária; são eles E. Cary ${ }^{14}$, J. P. Vinay e J. Darbelnet $^{15}(1958)$ e alguns anos antes, Valery Larbaud (1946).

Mounin $^{16}$ oferece em sua obra um estudo exaustivo da relação entre Linguística e tradução (capítulos 1,2 e 3 ) e esboça, em seguida, sua teoria em torno de três temas: o sentido, a visão do mundo e as múltiplas civilizações em torno da tradução. Entretanto, não descuida da tradução literária a que dedica vários artigos, em particular "La notion de qualité en matière de traduction littéraire" (1963). Mounin parte da ideia de J. Whatmou$\operatorname{gh}^{17}$ (1956) de que "os universais da linguagem são características comuns que encontramos em todas as línguas" e a relaciona com os universais linguísticos que não são mais que uma parte de um conceito ainda maior: os universais culturais. Lembramos desta frase de Mounin "repleta de significado": "A tradução é uma operação singular sobre a linguagem e o pensamento".

Com E. Cary nos encontramos com o profissional da tradução em exercício, em Genebra, (morreu em acidente de avião em 1966), que ofereceu dois livros importantes à comunidade científica: Comment faut-il traduire? (1953) e La traduction dans le monde moderne (1956). Cary se

\footnotetext{
${ }^{14}$ Edmond CARY. La traduction dans le monde moderne. Geneve, Georg et Cie, 1956.

${ }^{15}$ Jean Paul VINAY \& Jean DARBELNET. Stylistique comparée du français et de l'anglais. Paris, Didier, 1958.

${ }^{16}$ MOUNIN. op. cit.

17 Joshua Whatmough. Language. A modern synthesis. London, Secker \& Wartburg, 1956.
} 
vínculo de Lingüística y traducción, la traducción es siempre una operación de género, de campo, la traducción literaria es una operación literaria, no lingüística, dice Cary, y varias veces nos repite "la traducción es un arte, siempre un arte". Queda claro que la primacía en el buen traductor es su perfil de especialización: un dramaturgo será buen traductor de teatro, un poeta de poesía, etc.

El repaso que Cary ofrece, en la segunda obra citada, de la traducción en el mundo sirve al autor para reflexionar sobre los diferentes tipos de traducción. Dedica los capítulos V, VI, VII y VIII a la traducción literaria y realiza un repaso histórico sobre cómo se ha procedido en cada etapa. Traducir para Cary (1956: 18) «c'est être soi même capable de saisir les infinies résonances de chaque mot, de chaque mouvement de pensée, de chaque battement de coeur, et savoir le communiquer au lecteur, dont tout l'univers s'ordonne cependant selon un rythme antinomique ... Il s' agit d 'un art, irreductible a tout autre» (Traducción: ser capaz por uno mismo de captar las infinitas resonancias de cada palabra, de cada movimiento del pensamiento, de cada latido del corazón, y saber comunicarlo al lector, pues todo el universo se ordena según un ritmo antinómico ... Se trata de un arte, irreductible a otro).

En cuanto a la obra, múltiples veces citada, de J. J. Vinay \& J. Darbelnet $^{18}$, es referente importante en estos años al proponer una taxonomía de técnicas traductológicas bajo el nombre de traducción directa o literal y traducción oblicua. Cada uno de estos procedimientos opõe ao vínculo de Linguística e tradução; a tradução é sempre uma operação de gênero, de campo; a tradução literária é uma operação literária, não linguística, diz Cary, e várias vezes repete "a tradução é uma arte, sempre uma arte". Fica claro que a primazia no bom tradutor é seu perfil de especialização: um dramaturgo será bom tradutor de teatro, um poeta de poesia, etc.

A revisão que Cary oferece, na segunda obra citada, da tradução no mundo serve ao autor para refletir sobre os diferentes tipos de tradução. Dedica os capítulos V, VI, VII e VIII à tradução literária e realiza um estudo histórico sobre como se procedeu em cada etapa. Traduzir para Cary (1956: 18) ' $\mathrm{c}$ ' est être soimême capable de saisir les infinies résonances de chaque mot, de chaque mouvement de pensée, de chaque battement de coeur, et savoir le communiquer au lecteur, dont tout l'univers s'ordonne cependant selon un rythme antinomique ... Il s' agit d 'un art, irreductible a tout autre" (Tradução: é ser você mesmo capaz de entender as ressonâncias infinitas de cada palavra, de cada movimento do pensamento, de cada batimento do coração, e saber transmitir ao leitor, pois todo o universo se ordena segundo um ritmo antinômico ... Trata-se de uma arte, irredutível a qualquer outra).

No que se refere à obra de $\mathrm{J}$. J. Vinay \& J. Darbelnet ${ }^{18}$, inúmeras vezes citada, é uma referência importante nestes anos ao propor uma taxonomia de técnicas tradutológicas sob o nome de tradução direta ou literal e tradução oblíqua. Cada um destes procedimentos

\footnotetext{
${ }^{18}$ VINAY \& DARBELNET. op. cit.
} 
traductológicos ha sido objeto de numerosas publicaciones que se han ocupado de redefinir, ampliar, enriquecer el campo de actuación de cada técnica. Metodológicamente la obra se fundamenta en la Estilística comparada, en voga en aquellos años. Es por tanto otro referente para ubicar y valorar la aportación de Levý.

Finalmente, Valery Larbaud es también referente de este período. Citado por E. Cary (1963: 121131) entre los seis grandes traductores franceses (Les grands traducteurs français), por A. Horquelin (1981:189-192) en su Anthologie de la manière de traduire. Domaine français y por J. Delisle (1999: 207-236) en Portraits de traducteurs entre los nueve teóricos franceses más relevantes, Larbaud ha dado nombre a los Coloquios de la Asociación Internacional de Amigos de Valery Larbaud que tiene su sede en Vichy y en la Universidad de Clermond Ferrand II.

Larbaud nos ha dejado una obra (1946) Sous 1 'invocation de Saint Jérôme y muchas traducciones. Se trata de una serie de observaciones y consejos a los traductores, fruto de su experiencia de traductor. Gran viajero y conocedor de culturas, Larbaud fue traductor del inglés, del español y del italiano, siempre de obras literarias. Teoriza, reflexiona y entre las observaciones que nos da rechaza la traducción palabra a palabra pues el texto meta debe tener el sello francés, aunque encontramos fragmentos de traducción literal en sus traducciones. Prefiere, sin embargo, una traducción más literaria que literal. Ballard ${ }^{19}$ (1999: 232) califica a Larbaud de diletante y recuer- tradutológicos foi objeto de numerosas publicações que se ocuparam de redefinir, ampliar, enriquecer o campo de atuação de cada técnica. Metodologicamente a obra se fundamenta na Estilística comparada, em voga naqueles anos. É, portanto, outra referência para situar e valorizar a contribuição de Levý.

Finalmente, Valery Larbaud é também referência deste período. Citado por E. Cary (1963: 121131) entre os seis grandes tradutores franceses (Les grands traducteurs français), por A. Horquelin (1981: 189-192) em sua Anthologie de la manière de traduire. Domaine français e por J. Delisle (1999: 207-236) em Portraits de traducteurs entre os nove teóricos franceses mais relevantes, Larbaud deu nome aos Colóquios da Associação Internacional de Amigos de Valery Larbaud que tem sua sede em Vichy e na Universidade de Clermond Ferrand II.

Larbaud nos deixou a obra Sous 1 'invocation de Saint Jérôme (1946) e muitas traduções. Trata-se de uma série de observações e conselhos aos tradutores, fruto de sua experiência de tradutor. Grande viajante e conhecedor de culturas, Larbaud foi tradutor do inglês, do espanhol e do italiano, sempre de obras literárias. Teoriza, reflete e, entre as observações que nos dá, rechaça a tradução palavra por palavra, pois o texto meta deve ter a marca francesa, ainda que encontremos frag-mentos de tradução literal em suas traduções. Prefere, entretanto, uma tradução mais literária. Ballard ${ }^{19}$ (1999: 232) qualifica Larbaud de entusiasta e lembra que, para literatos e teóricos da

\footnotetext{
${ }^{19}$ BALLARD. op. cit., 232.
} 
da que para literatos y teóricos de la traducción de hoy se trata de un amateur, pero hay que reconocer, en los años que escribe sus reflexiones, que sus ideas eran válidas y siguen siéndolo por el trabajo cuidado y riguroso de sus traducciones literarias y por la profundidad de sus reflexiones.

Si tuviéramos que relacionar el pensamiento de estos cuatro autores francófonos con el pensamiento de Levý podríamos decir (1) que Mounin postula como Levý situar el proceso traductivo en el marco de la diferente visión del mundo que cada lengua personifica, por consiguiente, ambos evalúan los dos tipos de traducción literal y literaria y se decantan por el riguroso trabajo de "estilística" que debe asumir cualquier traductor que encare una traducción literaria.

(2) Otro tanto cabe decir de Cary y de Larbaud, pues Cary antepone la formación y calidad de estilo del traductor literario a cualquier otra consideración lingüística, ésta debe ser previa no simultánea, mientras que Larbaud llega incluso a postular "la infidelidad" en pro de un bello texto cuajado de calidad literaria. (3) La propuesta de Vinay y Darbelnet, inmersa en la estilística comparada, en voga en su momento, dibuja una propuesta de equilibrio entre texto origen y texto meta. Por tanto la teorización de Levý se inscribe dentro de la corriente europea y norteamericana que postula la concepción de la traducción como un proceso de decisiones sucesivas y como una actividad literaria. tradução de hoje, se trata de um amador, mas há que se reconhecer, nos anos que escreve suas reflexões, que suas ideias eram válidas e seguem sendo pelo trabalho cuidadoso e rigoroso de suas traduções literárias e pela profundidade de suas reflexões.

Se tivéssemos que relacionar o pensamento destes quatro autores francófanos com o pensamento de Levý, poderíamos dizer (1) que Mounin postula como Levý situar o processo tradutório no marco da diferente visão do mundo que cada língua personifica; por conseguinte, ambos avaliam os dois tipos de tradução literal e literária e se inclinam pelo rigoroso trabalho de "estilística" que deve assumir qualquer tradutor que encare uma tradução literária. (2) Outro tanto cabe dizer de Cary e de Larbaud, pois Cary prefere a formação e a qualidade de estilo do tradutor literário a qualquer outra consideração linguística; esta deve ser prévia e não simultânea, enquanto que Larbaud chega inclusive a postular "a infidelidade" em prol de um belo texto carregado de qualidade literária. (3) A proposta de Vinay e Darbelnet, imersa na estilística comparada, em voga nesse momento, descreve uma prosposta de equilíbrio entre texto origem e texto meta. Portanto a teorização de Levý se inscreve dentro da corrente européia e norte-americana que defende a concepção da tradução como um processo de decisões sucessivas e como uma atividade literária. 
2 La traducción de los nombres propios en el contexto español

A modo de apéndice deseo ofrecer un complemento al brillante artículo de la profesora Králová sobre el tema de la traducción de los nombres propios. Se trata de un breve comentario de trabajos que son hoy referencia en la investigación sobre este tema en España y en Francia.

En España la Fundación A1fonso X el Sabio, constituida por importantes académicos de la Real Academia Española (RAE) y catedráticos de diferentes universidades españolas (E. Bernárdez, J. Cantera, L. Cortés, F. J. Hernández y J. C. Santoyo) celebró un encuentro en la sede de la Asociación - la Biblioteca Nacional de Madrid para hablar de este tema, en 1983. De este debate se lanzó una publicación en 1987 con el título Problemas de traducción. Contamos también con la tesis de María Barros $\mathrm{Ochoa}^{20}$, otra publicación de Nelson Cartagena ${ }^{21}$, y finalmente la tesis doctoral de Javier Franco Aixela $^{22}$. Me voy a referir a este último trabajo.

La tesis de Franco plantea los condicionantes de traducción de los nombres propios estudiando, en primer lugar, el parámetro macrotextual (la historicidad, propósito y tipo de traducción, el iniciador, el traductor, la canonización, la retraducción), en segundo lugar, el parámetro microtextual (grado de explicitud, relevancia y recurrencia,

\section{A tradução dos nomes próprios no contexto espanhol}

Como adendo desejo oferecer um complemento ao brilhante artigo da professora Králová sobre o tema da tradução dos nomes próprios. Trata-se de um breve comentário de trabalhos que são hoje referência na pesquisa sobre o tema na Espanha e na França.

$\mathrm{Na}$ Espanha a Fundação Alfonso X o Sábio, formada por importantes acadêmicos da Real Academia Espanhola (RAE) e catedráticos de diferentes universidades espanholas (E. Bernárdez, J. Cantera, L. Cortés, F. J. Hernández e J. C. Santoyo), celebrou em 1983 um encontro na sede da Associação - a Biblioteca Nacional de Madri - para falar deste tema. Deste debate foi lanzada uma publicação em 1987 com o título Problemas de traducción. Contamos também com a tese de Maria Barros $\mathrm{Ochoa}^{20}$, outra publicação de Nelson Cartagena ${ }^{21}$ e, finalmente, a tese de doutorado de Javier Franco Aixela ${ }^{22}$. Vou me referir a este último trabalho.

A tese de Franco aborda os condicionantes de tradução dos nomes próprios estudando, em primeiro lugar, o parâmetro macrotextual (a historicidade, o propósito e o tipo de tradução, o iniciador, o tradutor, a canonização, a retradução), em segundo lugar, o parâmetro microtextual (grau de explicitude, relevância e recorrência,

\footnotetext{
${ }^{20}$ María BARROS OCHOA. La traducción de los nombres propios inglés-español. Teoría y práctica. Tesis doctoral, Universidad de León 1983.

${ }^{21}$ Nelson CARTAGENA. "Acerca de la traducción de los nombres propios en español (com especial referência ao alemão)", in Nelson CARTAGENA \& Cordelia SCHMIDT (Eds.). Miscelanea Antwerpiensia. Tübingen, Niemeyer 1992, 93-121.

${ }_{22}^{2}$ Javier FRANCO AIXELA. La traducción condicionada de los nombres propios inglés-español. Salamanca, Ediciones Almar 2000.
} 
coherencia, integración textual) y en tercer lugar, la naturaleza de los nombres propios (grado de sementacidad y opacidad, historial intralingüístico y consideraciones ideológicas).

Franco ha reunido un corpus rico y variado (literatura infantil, novela canónica, novela negra, novela rosa, poesía, ensayo y periodismo) y tras un detallado examen aplicando el esquema antes mencionado, llega a las conclusiones siguientes (ofrezco un resumen):

(1) la absoluta traducibilidad de los nombres propios aunque "no hay un solo texto entre los cincuenta estudiados en el que no se produzca algún tipo de modificación, siempre al menos del significante y casi siempre también cultural" [...], (2) la traducción es un proceso que se rige por al menos dos clases de restricciones: descontextualizaciones o lingüísticas y textuales [...], (3) no son los condicionantes de traducción citados los que establecen intrínsecamente la conveniencia de respetar o transgredir las traducciones por defecto, sino las divergencias que a partir de dichos condicionantes puedan existir entre lo ofrecido por el texto original y lo deseable en las nuevas condiciones de comunicación, [...] (4) las modificaciones impuestas por dichas divergencias son sistemáticamente hegemónicas frente a las normas por defecto, lo que implica en traducción una preferencia por la aceptabilidad (adaptación a las necesidades e intereses del lector término), [...] (5) las divergencias pueden adquirir un carácter macrotextual, afectando al conjunto de la obra, o microtextual afectando a segmentos concretos, [...] (6) el factor genérico por sí solo parece coerência, integração textual) e, em terceiro lugar, a natureza dos nomes próprios (grau de semantização e opacidade, historial intralinguístico e considerações ideológicas).

Franco reuniu um corpus rico e variado (literatura infantil, romance canônico, romance policial, ficção romântica, poesia, ensaio e jornalismo) e após um detalhado exame aplicando o esquema antes mencionado, chega às seguintes conclusões (ofereço um resumo):

(1) a absoluta traduzibilidade dos nomes próprios, embora "não haja um só texto entre os cinquenta estudados em que, pelo menos, não se tenha produzido sempre algum tipo de modificação do significante e quase sempre também cultural" [...], (2) a tradução é um processo regido por pelo menos duas classes de restrições: descontextualizações ou linguísticas e textuais [...], (3) não são os condicionantes de tradução mencionados os que estabelecem intrinsecamente como padrão a conveniência de respeitar ou violar as traduções, mas as divergências que a partir de tais condicionantes possam existir entre o oferecido pelo texto original e o desejável nas novas condições de comunicação, [...] (4) as modificações impostas por ditas divergências são sistematicamente hegemônicas como padrão frente às normas, o que implica, em tradução, uma preferência pela aceitabilidade (adaptação a necessidades e interesses do leitor final), [...] (5) as divergências podem adquirir um caráter macrotextual, afetando o conjunto da obra, ou microtextual afetando segmentos concretos, [...] (6) o fator genérico por si só parece ser um dos que menos determi- 
ser uno de los que menos determinan el modo de traducir, [...] (7) el factor histórico sí se halla vinculado directamente a las normas por defecto, a las que determina, [...] (8) la retraducción se revela como un proceso que potencia el aumento de conservación en las sucesivas versiones, [...] (9) lector y propósito de la traducción constituyen dos factores íntimamente unidos, [...] (10) el iniciador posee una capacidad casi ilimitada de intervención sobre la traducción, [...] (11) el factor canonización demuestra ser un catalizador de la conservación, si bien su peso específico como factor aislado parece tan relativo como el genérico, [...] (12) la naturaleza del nombre propio constituye habitualmente el elemento determinante en la distribución porcentual de las diversas estrategias de traducción. $[\ldots]^{23}$ (pp. 255-260).

Y así hasta 23 respuestas razonadas al problemático problema de la traducción de los nombres propios.

De las publicaciones francesas el mejor trabajo es el de Michel Ballard (2001) Le Nom Propre en Traduction. Un primer capítulo se ocupa del estudio del nombre propio como significante en donde se aborda los temas siguientes: los tipos de nombre propios, la transcripción y transliteración, la asimilación fonética y gráfica, la traducción más o menos literal, topónimos y referencias culturales, topónimos y antropónimos, juegos de palabras y la perspectiva histórica y las estratégicas de traducción. Los capítulos dos y tres tratan de la inserción textual del nombre propio y del sentido en un estudio profundo sobre ejemplos de traducción nam o modo de traduzir, [...] (7) o fator histórico se acha, sim, vinculado diretamente como padrão às normas, as quais determina, [...] (8) a retradução se revela como um processo que potencia o aumento de conservação nas sucessivas versões, [...] (9) leitor e propósito da tradução constituem dois fatores intimamente unidos, [...] (10) o iniciador possui uma capacidade quase ilimitada de intervenção sobre a tradução, [...] (11) o fator canonização demonstra ser um catalizador da conservação, ainda que seu peso específico como fator isolado pareça tão relativo como o genérico, [...] (12) a natureza do nome próprio constitui habitualmente o elemento determinante na distribuição percentual das diversas estratégias de tradução $[\ldots]^{23}$.

E assim até 23 respostas relacionadas com o complicado problema da tradução dos nomes próprios.

Das publicações francesas, o melhor trabalho é o de Michel Ballard, Le Nom Propre en Traduction (2001). Um primeiro capítulo se ocupa do estudo do nome próprio como significante, onde são abordados os seguintes temas: os tipos de nomes próprios, a transcrição e transliteração, a assimilação fonética e gráfica, a tradução mais ou menos literal, topônimos e referências culturais, topônimos e antropônimos, jogos de palavras e a perspectiva histórica e as estratégias de tradução. Os capítulos dois e três tratam da inserção textual do nome próprio e do sentido em um profundo estudo sobre exemplos de tradução inglês-francês.

\footnotetext{
${ }^{23}$ FranCO AIXELA. op. cit., 255-260.
} 
inglés- francés.

Otros trabajos conocidos, de investigación linguística, son los publicados en las Revistas Langages 66 (1982) y Langue française 92 (1991). De contenido traductológico pero de poca intensidad: Jiř́i Elman (1986) "Le problème de traduction des noms propres", $\mathrm{H}$. Van Hoof (1999) «Les noms de pays, de peuples et de lieux dans le langage imagé », y M. Voituriez (1994) « Le problème des noms propres $»$.

\section{Lingiiística y traducción: el antes} y el después

Esbozar un esquema que dé cuenta del camino recorrido en la investigación lingüística y traductológica desde la década de los sesenta hasta nuestro días resulta difícil pues mucho es lo publicado y como sucede en tantos otros campos científicos, nuevos paradigmas han surgido con fuerza obscureciendo no pocos trabajos que fueron pioneros en su tiempo. Trataré de sintetizar con brevedad algunas líneas de interés.

En primer lugar, retomamos de Amparo Hurtado ${ }^{24}$ su propuesta de clasificación de Enfoques lingüísticos. Se trata de modelos, dice la autora, basados en la aplicación de teorías lingüísticas que inciden en la descripción y comparación de lenguas sin entrar en consideraciones de índole textual. Son las siguientes:

(1) La lingüística comparada tradicional, heredera de los estudios diacrónicos, que utiliza las categorías de la gramática tradicional y efectúa comparaciones entre las lenguas de unidades aisladas. Por
Outros trabalhos conhecidos, de pesquisa linguística, são os publicados nas Revistas Langages 66 (1982) e Langue française 92 (1991). De conteúdo tradutológico, mas de pouca magnitude: Jiř́ Elman, Le problème de traduction des noms propres (1986), H. Van Hoof, Les noms de pays, de peuples et de lieux dans le langage imagé (1999), e M. Voituriez, Le problème des noms propres (1994).

3 Linguística e tradução: o antes e o depois

Esboçar um esquema que dê conta do caminho percorrido na pesquisa linguística e tradutológica desde a década de sessenta até os nossos dias resulta difícil, pois muito é o publicado e, como sucede em tantos outros campos científicos, novos paradigmas surgiram com força obscurecendo muitos trabalhos que foram pioneiros em seu tempo. Tratarei de sintetizar brevemente algumas linhas de interesse.

Em primeiro lugar, retomamos de Amparo Hurtado ${ }^{24}$ sua proposta de classificação de enfoques linguísticos. Trata-se de modelos, diz a autora, baseados na aplicação de teorias linguísticas que incidem na descrição e comparação de línguas sem entrar em considerações de índole textual. São as seguintes:

(1) A linguística comparada tradicional, herdeira dos estudos diacrônicos, que utiliza as categorias da gramática tradicional e efetua comparações entre as línguas de unidades isoladas. Por exemplo,

\footnotetext{
${ }^{24}$ Amparo HURTADO ALBIR. Traducción y traductología. Madrid, Cátedra 2001, 126-127.
} 
ejemplo la obra de V. García Yebra $^{25}$.

(2) Las estilísticas comparadas, que aplican al análisis comparado los estudios efectuados en estilística interna. Su mayor aportación, la obra de Vinay \& Darbelnet. También la obra de Malblanc aplicada al par de lenguas francésalemán, Vázquez Ayora (1977), Newmark (1988), Van Hoof, Ballard (1987), etc. ${ }^{26}$.

(3) Las comparaciones gramaticales entre lenguas ... utiliza diferentes modelos. Por ejemplo: Guillemin-Flescher (1981), Chuquet y Paillard (1989) etc.

(4) La aplicación al estudio de la traducción de diferentes modelos de análisis lingüístico. Garnier (1985) con la sistemática de Guillaume, Catford (1965) con las teorías de Halliday o el modelo transformacional de Vázquez Ayora (1977), etc. $\cos ^{27}$

(5) Los enfoques semánti-

(6) Los enfoques semánticos, que consideran la traducción como proceso de transformación entre sistemas de signos ${ }^{28}$.

Una clasificación lingüística de este tipo requiere matizaciones. En primer lugar el tema de las fechas de publicación, las obras reseñadas ocupan una franja temporal de casi cuarenta años en los que los a obra de V. García Yebra ${ }^{25}$.

(2) As estilísticas comparadas, que aplicam os estudos efetuados em estilística interna à análise comparada. Sua maior contribuição, a obra de Vinay \& Darbelnet. Também a obra de Malblanc aplicada ao par de línguas francêsalemão, Vázquez Ayora (1977), Newmark (1988), Van Hoof, Ballard (1987), etc. ${ }^{26}$.

(3) As comparações gramaticais entre línguas... utiliza diferentes modelos. Por exemplo: Guillemin-Flescher (1981), Chuquet e Paillard (1989) etc.

(4) A aplicação ao estudo da tradução de diferentes modelos de análise linguística. Garnier (1985) com a sistemática de Guillaune, Catford (1965) com as teorias de Halliday ou o modelo transformacional de Vázquez Ayora (1977), etc. $\cos ^{27}$

(5) Os enfoques semânti-

(6) Os enfoques semânticos, que consideram a tradução como processo de transformação entre sistemas de signos ${ }^{28}$.

Uma classificação linguística deste tipo requer matizações. Em primeiro lugar está o tema das datas de publicação, as obras resenhadas ocupam uma faixa temporal de quase quarenta anos em que

\footnotetext{
${ }^{25}$ Valentín GARCIA YEBRA. Teoría y práctica de la traducción. Madrid, Gredos 1982.

${ }^{26}$ VINAY \& DARBELnET. op. cit.; Alfred MALBlANC. Stylistique comparée du français et de l'allemand. Essai de représentation linguistique comparée et étude de traduction. Paris, Didier 1961; Gerardo VÁZQUEZ AYORA. Introducción a la traductologia. Washington, Georgetown University 1977; Michel BALLARD. La traduction: de I'anglais au français. Paris, Nathan 1987.

${ }^{27}$ Mildred LARSON. Meaning-based Translation. A Guide to Cross-Language Equivalence. Lanham, University Press of America 1984; Eugene NIDA. Exploring Semantic Structures. München, Wilhelm Fink 1975; Dionyz ĎURJŠIN. "Die Äquivalenz in der literarischen und nichtliterarischen Übersetzung", in Slavica Slovaca 7, 1972.

${ }^{28}$ Alexandur Konstantinov LJDUSKANOY. Prevezdat covekut $i$ masinata - Traduction humaine et traduction mécanique - Mensch und Maschine als Übersetzer. Paris; München; Halle, Dunod \& Association Jean-Favard pour le développment de la Linguistique Quantitative 1969; Enrico ARCAINI. Analisi linguistica e traduzione. Bologna, Patron 1986, etc.
} 
paradigmas lingüísticos han ido sucediéndose uno tras otro. Ubicar una obra en una escuela presupone el estudio profundo de la misma pues en investigación lingüística las teorías, los métodos y los diferentes paradigmas han ido sucediéndose paulatinamente a lo largo de la segunda mitad del siglo XX con trabajos punteros que marcan netamente el paso de un puente a otro. Creo que la clasificación que debe ofrecerse, si nos atenemos a la aplicación basada en una metodología lingüística, no puede ir más allá que "encajar" a los autores mencionados en alguno de los tres grandes paradigmas de investigación lingüística de este periodo: estructuralismo, generativismo $\mathrm{y}$ pragmática. Y el tercero entronca ya con los enfoques textuales que tan buen servicio ha dado en la investigación traductológica. Resulta extraño encontrar la obra de Vázquez Ayora $^{29}$ en dos epígrafes diferentes: en las estilísticas comparadas y en la aplicación de modelos de análisis lingüísticos.

La segunda observación se refiere a la reflexión traductológica. Los trabajos reseñados priorizan los postulados de la investigación linguística para acercarse a la traducción. Conviene ahora determinar cuáles son los ejes de esa aproximación y qué resultados nos han ofrecido, evaluar si siguen siendo válidos. Si gran parte de los autores citados por A. Hurtado ${ }^{30}$ son referentes todavía en la investigación traductológica, conviene señalar y explicar cuáles son los conceptos que pueden seguir siendo operativos. Avanzar en la relación entre Lingüística y Traducción es os paradigmas linguísticos foram se sucedendo um após o outro. Situar uma obra em uma escola pressupõe o estudo profundo da mesma, pois, em pesquisa linguística, as teorias, os métodos e os diferentes paradigmas foram se sucedendo paulatinamente ao longo da segunda metade do século XX com trabalhos de destaque que marcam claramente a passagem de um lugar a outro. Creio que a classificação que deve ser oferecida, se nos atemos à aplicação baseada numa metodologia linguística, não pode ir mais além do que "encaixar" os autores mencionados em algum dos três grandes paradigmas de pesquisa linguística deste período: estruturalismo, gerativismo e pragmática. E o terceiro se relaciona já com os enfoques textuais que tão bom serviço prestaram à pesquisa tradutológica. É estranho encontrar a obra de Vázquez Ayora ${ }^{29}$ em duas epígrafes diferentes: nas estilísticas comparadas e na aplicação de modelos de análises linguísticas.

A segunda observação se refere à reflexão tradutológica. Os trabalhos resenhados priorizam os postulados da pesquisa linguística para se aproximarem da tradução. Convém agora determinar quais são as bases dessa aproximação e que resultados nos ofereceram; avaliar se continuam sendo válidos. Se grande parte dos autores citados por A. Hurtado ${ }^{30}$ são referências ainda na pesquisa tradutológica, convém destacar e explicar quais são os conceitos que podem continuar sendo operativos. Avançar na relação entre Línguística e Tradução é avaliar a viabilidade das pro-

\footnotetext{
${ }^{29}$ VAZQUEZ AYORA. op. cit.

${ }^{30}$ HURTADO ALBIR. op. cit.
} 
evaluar la viabilidad de las propuestas conocidas.

\section{Conclusión}

Nuestro trabajo ha intentando reflejar una aproximación al conocimiento del pensamiento traductológico de J. Levý, no suficiente y limitada a los textos reseñados. A continuación hemos intentado poner en relación algunos trabajos de origen francés y de la misma época con la teoría de Levý, y no lo hacemos con trabajos publicados en España porque no los conocemos en ese mismo periodo. Recuerdo que la obra de Mounin ${ }^{31}$ fue traducida al español el mismo año de su publicación en Francia en la Editorial Gredos de Madrid porque el público universitario sentía una necesidad vital de acceder a este tipo de trabajos. También hemos reflexionado sobre el tema de la traducción de los nombres propios tomando como punto de partida el brillante trabajo de la profesora Králová y finalmente, hemos tratado de esbozar el complejo paradigma Lingüística y traducción, complejo por varios motivos: a) los primeros trabajos serios de traductología en el siglo XX se apoyan en la Lingüística, pero en diferentes paradigmas, b) la traductología ha asumido la reflexión textual y comunicativa como clave de sus investigaciones y algo hay de lingüístico en estas aproximaciones, pues en el principio era "el texto" y c) no contamos con trabajos que evalúen tantas aportaciones brillantes de corte lingüístico y señalen qué conceptos son operativos para el buen traductor de hoy en día. En cuanto al pensamiento de Levý sobre la postas conhecidas.

\section{Conclusão}

Nosso trabalho procurou fazer um primeiro contato com o conhecimento do pensamento tradutológico de J. Levý, não presunçoso e limitado aos textos resenhados. Em seguida tentamos relacionar alguns trabalhos de origem francesa e da mesma época com a teoria de Levý, e não o fizemos com trabalhos publicados na Espanha, nesse mesmo período, porque os desconhecemos. Lembro que a obra de Mounin ${ }^{31}$ foi traduzida ao espanhol no mesmo ano de publicação na França, pela Editorial Gredos de Madri, porque o público universitário sentia uma necessidade básica de ter acesso a esse tipo de trabalho. Também discorremos sobre o tema da tradução dos nomes próprios, tomando como ponto de partida o brilhante trabalho da professora Králová e, finalmente, tratamos de esboçar o complexo paradigma Linguística e tradução; complexo por vários motivos: a) os primeiros trabalhos sérios de tradutologia no século $\mathrm{XX}$ se apoiam na Linguística, mas em diferentes paradigmas, b) a tradutologia assumiu a reflexão textual e comunicativa como elemento fundamental de suas pesquisas, e há algo de linguístico nestas abordagens, pois no princípio era "o texto" e c) não contamos com trabalhos que avaliem tantas contribuições brilhantes de corte linguístico e digam que conceitos são operativos para o bom tradutor hoje em dia. Quanto ao pensamento de Levý sobre a tradução, o ato de

\footnotetext{
${ }^{31}$ MounIN. op. cit.
} 
traducción acto de comunicación y la necesaria "empatía" entre autor y traductor son aspectos muy importantes y a los que se presta hoy día mucha atención, convendría pues estudiar los textos de Levý y relacionarlos con la investigación reciente. comunicação e a necessária "empatia" entre autor e tradutor são aspectos bem importantes e aos que hoje em dia se presta muita atenção; assim seria útil estudar os textos de Levý e relacioná-los com a pesquisa recente.

Fernando Navarro Domínguez tra.fnavarro@ua.es Prof. doutor, Universidade de Alicante (Espanha)

Fonte: "Jiří Levý: la teoría de la traducción y la lingüística" in Králová, Jana (ed.), Posibilidades y Límites de la Comunicación Intercultural. Ibero-Americana Pragensia - Supplementum, 27/2011.

Tradução de:

Andréa Cesco andrea.cesco@gmail.com Prof. doutora, Universidade Federal de Santa Catarina 